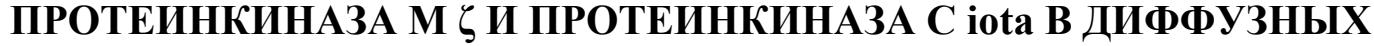 АСТРОЦИТОМАХ, АНАПЛАСТИЧЕСКИХ АСТРОЦИТОМАХ И ГЛИОБЛАСТОМАХ
}

\author{
Никитин П.В. ${ }^{1}$, Рыжова М.В. ${ }^{1}$, Галстян С.А. ${ }^{1}$, Зубова И.В. ${ }^{1}$, Хохлова Е.А. ${ }^{1}$ \\ ${ }^{1}$ ФГАУ «НМИЦ нейрохирургии имени акад. Н.Н. Бурденко» Mосква, е-mail: redseadog@gmail.com
}

Новообразования головного мозга, в частности глиальные опухоли, являются одной из самых серьезных проблем в современной онкологии. В рамках наших предыдущих исследований мы выявили, что

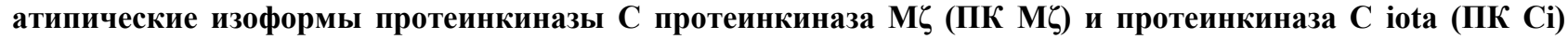
могут играть существенную роль в патогенезе глиом. Целью данного исследования явилось изучение и сравнительный анализ активности экспрессии ПК М и ПК Сі в диффузных астроцитомах, IDHмутантных (ДА), анапластических астроцитомах, IDH-мутантных (АА), и глиобластомах, IDH-дикого типа (ГБ), исследованных иммуногистохимическим методом и с помощью ПЦР в реальном времени, а также выявление связи активности экспрессии данных факторов с прогнозом пациентов. В целом нам удалось показать, что наименьшая активность экспрессии ПК МЦ выявляется в ДА, возрастает в АА и наибольшее значение наблюдается в ГБ. Наименышее значение активности экспрессии ПК Сі выявляется в ДА и АА, между которыми нет значимых различий, в ГБ значение данного показателя возрастает. Также было показано, что активность экспрессии ПК МЦ значимо влияет на общую выживаемость (ОВ) пациентов с ДА, АА и ГБ и на безрецидивную выживаемость (БРВ) в ДА и АА. В то же время активность экспрессии ПК Сі значимо влияет на ОВ и БРВ только при ГБ. Наши результаты могут иметь большую фундаментальную и практическую значимость.

Ключевые слова: протеинкиназа Мל, протеинкиназа C iota, диффузная астроцитома, анапластическая астроцитома, глиобластома.

\section{PROTEIN KINASE M $\zeta$ AND PROTEIN KINASE C iota IN DIFFUSE ASTROCYTOMAS, ANAPLASTIC ASTROCYTOMAS AND GLIOBLASTOMAS}

\author{
Nikitin P.V. ${ }^{1}$, Ryzhova M.V. ${ }^{1}$, Galstyan S.A. ${ }^{1}$, Zubova I.V. ${ }^{1}$, Khokhlova E.A. ${ }^{1}$ \\ IB Burdenko Neurosurgical Institute, Moscow, e-mail: redseadog@gmail.com
}

Brain tumors, in particular glial tumors, are one of the most serious problems in modern oncology. In our previous studies, we found that the atypical isoforms of protein kinase $C$ protein kinase $M \zeta(P K M \zeta)$ and protein kinase $\mathrm{C}$ iota (PK Ci) can play a significant role in the pathogenesis of gliomas. The aim of this research was to study and compare the expression activity of $\mathrm{PK} M \zeta$ and PK $\mathrm{Ci}$ in diffuse astrocytomas, IDH mutant (DA), anaplastic astrocytomas, IDH mutant (AA), and glioblastomas, IDH wild-type (GB), with immunohistochemical method and using real-time PCR, as well as the identification of the relationship of the expression activity of these factors with the patients survival. In general, we were able to show that the lowest activity of PK M $\zeta$ expression is detected in DA, it increases in AA, and the highest value is observed in GB. The lowest value of PK Ci expression activity is detected in DA and AA, between which there are no significant differences, in GB the value of this indicator increases. It was also shown that the activity of PK M $\zeta$ expression significantly affects overall survival (OS) in patients with DA, AA and GB, and on relapse-free survival (RFS) in DA and AA. At the same time, the expression activity of PK Ci significantly affects OS and RFS only in GB. Our results can be of great fundamental and practical significance.

Keywords: protein kinase $\mathrm{M} \zeta$, protein kinase $\mathrm{C}$ iota, diffuse astrocytoma, anaplastic astrocytoma, glioblastoma.

Опухоли головного мозга являются одной из самых серьезных проблем в современной онкологии. Глиальные опухоли, наряду с менингиомами, занимают лидирующие позиции в эпидемиологической структуре первичных опухолей центральной нервной системы (ЦНС), составляя в совокупности $35.5 \%$, при этом $15.6 \%$ от этого объема приходится на глиобластомы [1]. Показатели заболеваемости для глиальных опухолей зависят от гистологического типа, возраста в момент постановки диагноза, пола, этнической 
принадлежности и места жительства. По усредненным данным, заболеваемость всеми типами глиальных опухолей составляет 4,67-5,13 на 100000 человек. Усредненные по возрасту показатели заболеваемости для глиобластом составляют 0,89-3,69 на 100000 человек [1].

Основные акценты в классификации опухолей ЦНС ВОЗ (2016) сделаны на молекулярно-биологических факторах, поскольку именно в генетических, эпигенетических и молекулярно-биологических свойствах опухоли скрыты ответы на основные, до сих пор не разрешенные вопросы диагностики и лечения. При этом как с диагностической, так и с лечебной целью рассматриваются совершенно различные молекулярные звенья онкогенеза: факторы роста и их рецепторы, апоптозные и антиапоптозные белки, системы репарации ДНК, транскрипционные факторы, генетические мутационные изменения, эпигенетические модификации. В то же время невозможно зачастую выделить один конкретный механизм, делающий данную опухоль уникальной, её индивидуальность определяется сложным переплетением и пересечением различных механизмов и факторов, что ставит перед нами непростую задачу - необходимо найти маркеры, отражающие не просто наличие, например, той или иной мутации, но, в первую очередь, её функциональные последствия, то есть маркер, таким образом, должен не только быть связан с теми или иными протеомическими, генетическими или эпигенетическими изменениями, он должен точно характеризовать функциональное состояние основных клеточных процессов, на которые вышеперечисленные изменения влияют.

Наиболее подходящими на эту роль выглядят такие белки, как протеинкиназы различных классов и сопряженные с ними молекулярные факторы. Они являются главными эффекторами подавляющего большинства внутриклеточных процессов, играя ключевую роль в реализации основных функций опухолевых клеток, значимых для канцерогенеза. Исследования, посвященные участию различных протеинкиназ в развитии опухолей ЦНС, проводились, однако, существенным недостатком этих исследований является их фрагментарность, они не носят системного характера. Это касается и атипических изоформ протеинкиназы C, их роль в патогенезе глиальных опухолей головного мозга остается крайне мало изученной. При этом они выглядят перспективным объектом для исследований, способным в значительной мере изменить подходы к диагностике и лечению глиальных опухолей, поскольку обладают поистине уникальными свойствами.

Атипические изоформы протеинкиназы С не требуют для своей активации ни Са2+, ни диацилглицерола. К членам данного семейства относятся такие протеинкиназы, как

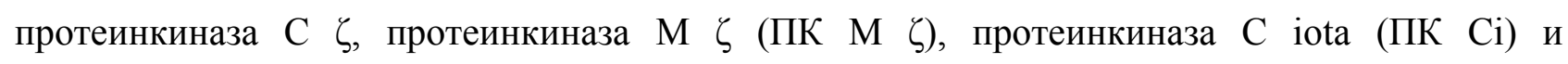
протеинкиназа C $\lambda$ [2]. Данные ферменты обладают необычными свойствами, в частности 
более высокой, чем у других представителей их класса, каталитической активностью [2]. Поскольку атипические изоформы протеинкиназы С не требуют для своей активации никаких дополнительных кофакторов, они, в отличие от большинства других протеинкиназ, могут выступать не только в качестве вторичных посредников в реализации различных функций, но и в качестве независимых и самостоятельных регуляторов этих функций, в том числе метаболических и пролиферативных процессов.

При этом ПК М Ц мозгоспецифична и является, в отличие от вышеуказанных протеинкиназ, специальным, функционирующим только в клетках головного мозга ключевым эффектором, реализующим различные внутриклеточные функции. Кроме того, ПК М 丂 обладает свойством самоподдержания собственной активности, что определяет возможность конститутивного и автономного её функционирования [3] и вовлечения в деятельность ключевых молекулярно-биологических каскадов в опухоли. Здесь нельзя не отметить, что в физиологических условиях ПК М протяжении длительного времени пластических перестроек в клетках и их стабильное функционирование в условиях меняющейся функциональной нагрузки [3]. То есть, исходя из биохимических и физиологических свойств данной протеинкиназы, она может выступать не только ключевым эффектором в функционировании целого ряда важнейших метаболических, сигнальных и пролиферативных каскадов в опухолевых клетках, но и одним из центральных регуляторов этих процессов, реализуя их в специфичной, отличной от других тканей и типов клеток манере.

Что касается опухолей головного мозга, то исследований роли ПК М новообразований данной локализации не проводилось. Тем не менее было обнаружено, что ПК М вовлекается в процессы пролиферации нейронов при нейрогенезе и может участвовать в пролиферативных каскадах в клетках астроцитарной глии [4]. Данные исследования показывают перспективность рассмотрения роли этих протеинкиназ в развитии опухолей головного мозга.

Высокая активность ПК Сі наблюдается в клетках аденокарциномы пищевода, стимулируя процесс пролиферации опухолевых клеток и подавляя процессы апоптоза в них [5]. При раке поджелудочной железы разработаны несколько перспективных препаратов, ингибирующих данную разновидность протеинкиназ. Также была показана роль ПК Сі в развитии и других опухолей. В некоторых исследованиях была выявлена роль ПК Сі в развитии глиобластомы [6]. Это привело к тому, что при данном виде опухолей именно ПК Сі стала наиболее перспективным объектом терапевтических воздействий. Так, применение такого препарата, как ауротиомалат, снижающего продуктивность каскадного пути ПК $\mathrm{Ci}$, позволило уменьшить инвазивность опухоли и вызвать ее регресс [7]. Использование 
специального ингибитора данной формы протеинкиназ ICA-1 приводит к значительному уменьшению объема опухоли [8]. В то же время исследований, выявляющих участие ПК Сі в патогенезе различных видов глиальных опухолей, не проводилось.

Таким образом, целью нашего исследования явилось изучение и сравнительный анализ активности экспрессии ПК М и ПК Сі в диффузных астроцитомах, IDH-мутантных, анапластических астроцитомах, IDH-мутантных, и глиобластомах, IDH-дикого типа, а также выявление связи активности экспрессии данных факторов с прогнозом пациентов.

\section{Материалы и методы исследования}

Общая характеристика исследования

Образцы диффузной астроцитомы, IDH-мутантной (ДА), анапластической астроцитомы, IDH-мутантной (AA), глиобластомы, IDH-дикого типа (ГБ) были получены у пациентов при хирургическом вмешательстве в НМИЦ нейрохирургии им. акад. Н.Н. Бурденко в 2014-2016 годах. В послеоперационном периоде пациенты проходили регулярные осмотры и получали стандартные схемы химио- и лучевой терапии. Средний возраст пациентов с ДА на момент операции составлял $38.28 \pm 4.84$ года, с АА $-42.48 \pm 2.32$ года, с ГБ - 62.46 \pm 4.28 года. Средние значения показателя безрецидивной выживаемости (БРВ) в ДА составили 48.54 \pm 8.34 месяца, в АА равнялись $36.28 \pm 4.52$ месяца, в ГБ равнялись $8.62 \pm 2.38$ месяца и общей выживаемости (OB) в среднем в ДА составили $145.52 \pm 18.84$ месяца, в АА равнялись $124.48 \pm 16.54$ месяца, в ГБ составили $18.26 \pm 4.46$ месяца. Материалы всех пациентов были подвергнуты тщательному патогистологическому и молекулярногенетическому исследованию для установления диагноза. Всего в исследование были включены по 60 образцов ДА, АА и ГБ. Методология исследования соответствовала стандартам, установленным Хельсинкской декларацией.

\section{Проведение иммуногистохимического исследования}

Из парафиновых блоков с фиксированными в них образцами опухолей изготавливали срезы толщиной 3 микрометра, депарафинировали с использованием ксилола и повторно гидратировали с помощью различных концентраций этанола, срезы высушивали в термостате при $45^{\circ} \mathrm{C}$. Затем срезы последовательно инкубировали с кроличьими моноклональными антителами против антигена ПК М 丂 человека (Аbcam, Великобритания) и после этого конъюгировали с антикроличьими мышиными IgG антителами против пероксидазы хрена (Cell Marque, «Sigma-Aldrich», США). Аналогичным образом срезы последовательно инкубировали с кроличьими моноклональными антителами против антигена ПК Сi человека (Аbcam, Великобритания), и после этого конъюгировали с антикроличьими мышиными IgG антителами против пероксидазы хрена (Cell Marque, «Sigma-Aldrich», США). Сайты связывания антител визуализировали с использованием 
тетрагидрохлорида 3,3'-диаминобензидина (Ventana Medical Systems, США), ядра клеток окрашивали гематоксилином.

\section{Обработка результатов иммуногистохимического исследования}

Образцы изучались под световым микроскопом на увеличении х400 тремя опытными патологами, не знакомыми с исходными данными пациентов. Активность экспрессии ПК М и ПК Сі подсчитывали полуколичественным методом, для чего процент клеток со слабоположительным окрашиванием (низкая интенсивность экспрессии) умножался на один, процент клеток с умеренно положительным окрашиванием (средняя интенсивность экспрессии) умножался на два, и, наконец, процент клеток с сильно положительным окрашиванием (высокая интенсивность экспрессии) умножался на три, после чего результат суммировался аналогично методике histoscore. Данные, полученные при подсчете тремя патологами, усреднялись.

\section{Извлечение РНК}

РНК экстрагировали тотально из образцов опухоли, фиксированных в парафиновых блоках, с использованием AllPrep DNA/RNA Kit (Qiagen, Hilden, Germany). Концентрацию и качество выделенной РНК измеряли с помощью спектрофотометра NanoDrop 1000, образцы РНК хранили при $-80{ }^{\circ} \mathrm{C}$ перед проведением анализа. Целостность РНК оценивали на Agilent Bioanalyzer (Agilent Technologies, США).

\section{Количественная ПЦР}

Экспрессия ПК МЦ и ПК Сі анализировалась во всех 180 образцах опухоли с использованием количественной ПЦР с обратной транскриптазой (qRT-ПЦР), праймеры были сконструированы и синтезированы IDT (США). Вся РНК опухолевых клеток (1 мкг) была обратно транскрибирована с применением набора обратной транскрипции кДНК (LifeTech, США). qRT-ПЦР проводили с использованием SYBR Select Master Mix (LifeTech) в 384-луночном планшете с использованием QuantStudio 5 Real-Time PCR System (Thermo Fisher Scientific, США). В каждом ПЦР миксе объемом 10 мкл содержалось 0.5 мкл кДНК матрицы, 200 нМ праймеров и 5 мкл мастер-смеси SYBR для ПЦР. Реакция включала в себя стадию нагрева до $50{ }^{\circ} \mathrm{C}$ в течение 2 минут, затем нагрев до $95^{\circ} \mathrm{C}$ в течение 2 минут для активации Таq-полимеразы, 40 циклов при $95^{\circ} \mathrm{C}$ в течение 15 с и $60{ }^{\circ} \mathrm{C}$ в течение 60 с и $60{ }^{\circ} \mathrm{C}$ в течение 1 минуты. Для каждого образца пороговый цикл $(\mathrm{Ct})$ определялся в трех вариантах. Экспрессия ПК МЦ и ПК Сі была нормализована по отношению к GAPDH, для выявления относительной активности экспрессии применялся индекс экспрессии, рассчитанный по

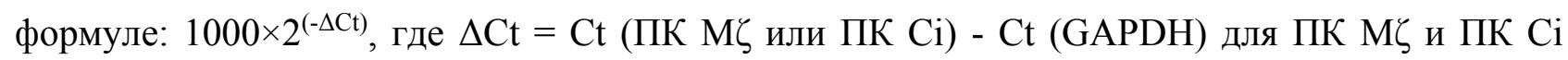
соответственно. Праймеры для ПЦР имели нуклеотидную последовательность 5'TGAAGGTGACCCTTGTACTGTG-3' (прямой) и 5'-CGGTATAGCTTCCTCCATCTTC-3' 
(обратный) для ПК М 5'-GGTTGTATCTCCTGGCCGTAAT-3' (обратный) для ПК $\mathrm{Ci}$, a также 5'• GTCAAGGCTGAGAACGGGAA• 3' (прямой) и 5'•AAATGAGCCCCAGCCTTCTC• 3' (обратный) для GAPDH.

Статистический анализ

Сравнение средних двух выборок проводилось при помощи U-теста Манна - Уитни. Связь экспрессии ПК М и ПК Сі с БРВ и ОВ при разных видах диффузных глиом была проанализирована с использованием метода Каплана - Мейера и логарифмического теста. Для определения отношения рисков (ОР) и 95\% доверительного интервала между риском рецидива или смерти и активности экспрессии ПК МЦ и ПК Сі использовались одномерные и многофакторные регрессионные модели пропорциональных рисков Кокса. Все статистические тесты были выполнены с использованием программного обеспечения SPSS Statistics 22 (IBM, США). Значения $p<0.05$ считались статистически значимыми.

Результаты иммуногистохимического исследования экспрессии ПК МЦ

В рамках проведенного исследования мы изучили активность экспрессии ПК МЦ в ДА, АА и ГБ полуколичественным иммуногистохимическим методом. Мы выявили, что активность экспрессии ПК М в ДА в среднем составила $46.48 \pm 2.34 \%$, в АА данный показатель равнялся $68.23 \pm 4.38 \%$, в ГБ он составил $110.46 \pm 4.37 \%$. При этом активность экспрессии ПК М б была статистически значимо ниже в ДА по сравнению с АА (p=0.00358; $\mathrm{Z}=4.32)$ и ГБ $(\mathrm{p}<0.00001 ; \mathrm{Z}=5.12)$. Также наблюдались значимо более низкие параметры активности экспрессии ПК М в АА по сравнению с ГБ (р=0.00004; Z=4.86).

Таким образом, самая высокая активность экспрессии наблюдалась именно в ГБ, далее по уровню активности следовали АА, наименьшая активность наблюдалась в ДА (рис. $1)$. 


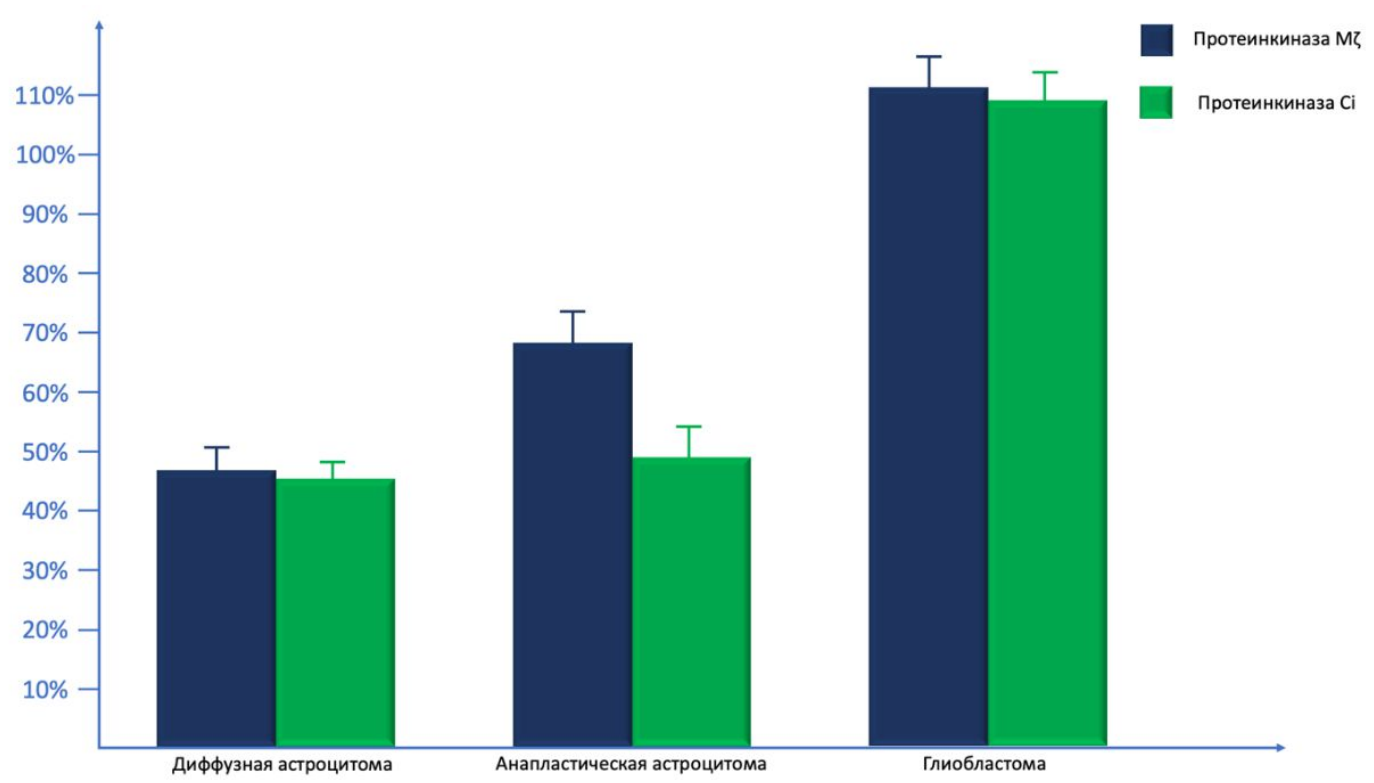

Pис. 1. Подсчет активности экспрессии протеинкиназы МЦ и протеинкиназы $C$ iota 8 диффузных астрочитомах, анапластических астроцитомах и глиобластомах с помощью полуколичественного метода histoscore

\section{Результаты иммуногистохимического исследования экспрессии ПК Сi}

Также мы рассмотрели вопрос изучения активности экспрессии ПК Сі в ДА, АА и ГБ. Мы показали, что активность экспрессии ПК Сі в ДА в среднем равна $45.46 \pm 2.38 \%$, в АА данный параметр составил $48.26 \pm 4.53 \%$, в то время как в ГБ он равнялся $108.44 \pm 4.71 \%$. При этом активность экспрессии ПК Сі значимо не различалась в ДА по сравнению с АA $(\mathrm{p}=0.08674 ; \mathrm{Z}=2.38)$, при этом с ГБ наблюдалось значимое различие $(\mathrm{p}<0.00001 ; \mathrm{Z}=5.14)$. Кроме того, параметры активности экспрессии ПК МЦ в АА были значимо ниже по сравнению с ГБ $(\mathrm{p}<0.00001 ; \mathrm{Z}=5.16)$.

В целом наиболее низкие значения активности экспрессии ПК Сі наблюдались в ДА и $\mathrm{AA}$, в то время как в ГБ данный показатель был существенно выше (рис. 1).

Результаты количественной ПЦР в реальном времени для мРНК ПК МЦ

При проведении ПЦР в реальном времени было выявлено, что содержание мРНК ПК М з значимо выше в ГБ по сравнению с ДА ( $\mathrm{p}=0.00034 ; \mathrm{Z}=4.32$ ), а также с АA ( $\mathrm{p}=0.00186$; $\mathrm{Z}=3.58$ ). Более того, данный параметр в АА значимо выше по сравнению с ДА ( $\mathrm{p}=0.00438$; $Z=4.48)$.

Таким образом, наибольшая выраженность экспрессии мРНК ПК МЦ наблюдается в ГБ, в то время как вслед за ними идут АА, наименьший уровень экспрессии выявляется в ДА (рис. 2). 


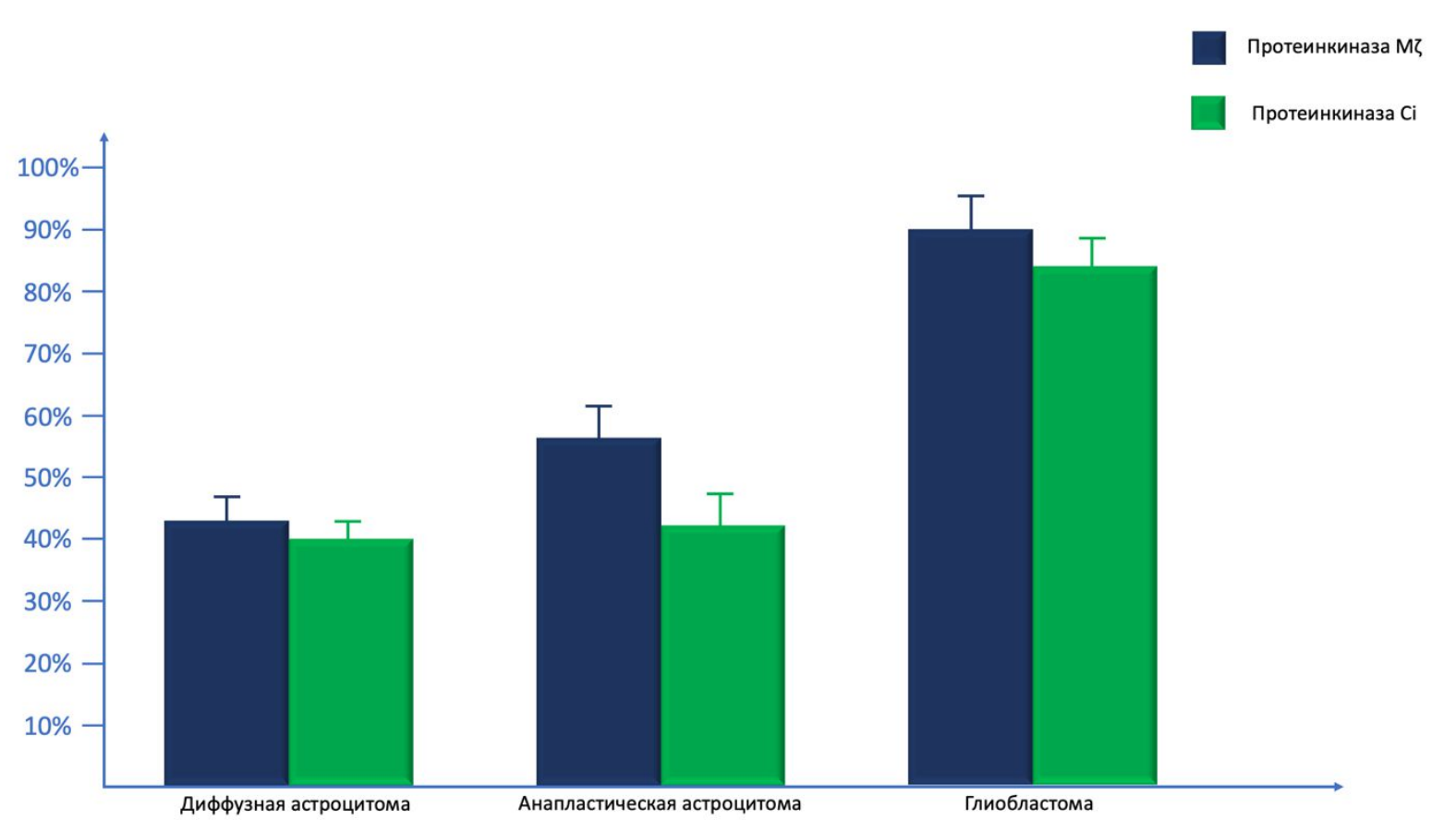

Рис. 2. Результаты проведения количественной ПЦР в реальном времени для мРНК протеинкиназы МЦи протеинкиназы C іота в диффузных астроцитомах, анапластических астроцитомах и глиобластомах

Результаты количественной ПЦР в реальном времени для мРНК ПК Сi

В рамках нашей работы мы провели количественную ПЦР в реальном времени, с помощью которой оценивали активность экспрессии мРНК ПК Сі в исследованных образцах опухоли. В результате нами было показано, что мРНК ПК Сi наиболее активно экспрессируется в ГБ, активность экспрессии мРНК ПК Сі в ГБ значимо выше по сравнению c $\mathrm{AA}(\mathrm{p}=0.00052 ; \mathrm{Z}=4.28)$, а также ДА ( $\mathrm{p}=0.00048 ; \mathrm{Z}=4.36)$. Тем не менее значимых различий по данному параметру между АА и ДА не наблюдалось ( $\mathrm{p}=0.08526 ; \mathrm{Z}=2.14)$.

В целом наиболее высокий уровень мРНК ПК Сі наблюдается в ГБ, в то время как в АА и ДА данный показатель значимо ниже (рис. 2).

Анализ влияния активности экспрессии ПК МЦ и ПК Сі на выживаемость паџиентов

При проведении анализа влияния экспрессии ПК МЦ и ПК Сі на прогноз пациентов выяснилось, что как уровни мРНК, так и иммуногистохимическая активность экспрессии ПК М з значимо влияют на ОВ пациентов с ДА (для иммуногистохимии $\mathrm{p}=0.00024$, OP 0.29, 95\% доверительный интервал 0.09-0.90, для мРНК $\mathrm{p}=0.00032$, ОР 0.38, 95\% доверительный интервал 0.1-0.8), АА (для иммуногистохимии $\mathrm{p}=0.00048$, ОР 1.0005, 95\% доверительный интервал 1.002-1.008, для мРНК $\mathrm{p}=0.00052$, ОР 1.03, 95\% доверительный интервал 1.025 1.035 ) и ГБ (для иммуногистохимии $\mathrm{p}=0.00564$, ОР $1.24,95 \%$ доверительный интервал 1.05 1.47 , для мРНК $\mathrm{p}=0.00582$, ОР 1.20, 95\% доверительный интервал 1.01-1.43). В то же время 
оба показателя активности ПК МЦ влияют на БРВ только в ДА (для иммуногистохимии $\mathrm{p}=0.00438$, ОР 0.45, 95\% доверительный интервал 0.37-0.54, для мРНК $\mathrm{p}=0.00621$, ОР 0.63, 95\% доверительный интервал 0.55-0.71) и АА (для иммуногистохимии $\mathrm{p}=0.00071$, ОР 0.32 , 95\% доверительный интервал 0.12-0.86, для мРНК $\mathrm{p}=0.00078$, ОР 0.42, 95\% доверительный интервал 0.08-0.94).

В то же время для ПК Сі характерна другая закономерность - уровни активности иммуногистохимической экспрессии и мРНК значимо влияют только на ОВ пациентов с ГБ (для иммуногистохимии $\mathrm{p}=0.00064$, ОР 0.56, 95\% доверительный интервал 0.16-0.88, для мРНК $\mathrm{p}=0.00056$, ОР 0.48, 95\% доверительный интервал 0.14-0.86). При этом активность ПК Сі взаимосвязана с БРВ также только у пациентов с ГБ (для иммуногистохимии $\mathrm{p}=0.00448$, ОР 0.62, 95\% доверительный интервал 0.18-0.84, для мРНК $\mathrm{p}=0.00436$, ОР 0.36, 95\% доверительный интервал 0.08-0.92).

В нашей работе мы впервые провели сравнительное аналитическое исследование активности экспрессии ПК М и ПК Сі в диффузных глиомах различной степени злокачественности. При этом мы показали, что активность экспрессии данных факторов поступательно возрастает с увеличением степени злокачественности опухоли как на протеомном, так и генетическом уровне. В то же время данная закономерность демонстрирует наличие одного исключения в отношении ПК $\mathrm{Ci}$, для которой не выявлено значимой разницы активности экспрессии между ДА и АА. Тем не менее в целом данная тенденция прослеживается достаточно четко и может свидетельствовать в пользу значительной роли атипических изоформ протеинкиназы С в патогенезе глиом. Полученные данные, кроме того, согласуются с нашими более ранними работами [9; 10].

При оценке влияния рассматриваемых параметров на БРВ и ОВ пациентов также были замечены несколько любопытных моментов. В частности, активность экспрессии ПК М же время ПК Сі значимо влияет на ОВ и БРВ только в случае ГБ, что может свидетельствовать о более высокой роли именно ПК М в обеспечении и поддержании злокачественных свойств глиом. В то же время эти данные согласуются с существующими исследовательскими работами, показавшими эффективность ингибиторов ПК Сі именно в случае наличия ГБ [7; 8]. Данный факт может служить своеобразным клиническим подтверждением сделанных на базе результатов нашей фундаментальной работы выводов. Тем не менее требуются дополнительные исследования по данном вопросу, чтобы более точно оценить роль данной протеинкиназы в процессах канцерогенеза.

Более того, в фундаментальной плоскости мы также выявляем довольно любопытную закономерность. В рамках нынешней и предыдущих работ нам удалось показать, что так или 
иначе ПК МЦ и ПК Сі значимы для патогенеза большинства глиальных новообразований. Подобный результат может быть следствием происхождения большинства глиом из нейрональных стволовых клеток. Ранее было показано, что атипические изоформы протеинкиназы C могут принимать непосредственное участие в процессах нейрогенеза и дифференцировки нейронов и клеток глии на стадии ранних предшественников. Современные патогенетические концепции, рассматривающие механизмы возникновения глиом, считают данные нейрональные и глиальные предшественники возможным субстратом формирования новообразования. Таким образом, наши результаты могут быть связаны не только с механизмами прогрессирования патологии, но также с особенностями еe возникновения и развития на ранних стадиях.

\section{Заключение}

В рамках настоящего исследования мы продолжили изучение темы роли ПК МЦ и ПК Сi в развитии и прогрессировании глиом. Рассмотрев в сравнительном молекулярном количественном аспекте данный вопрос, мы смогли показать перспективность данных молекулярных факторов как для дальнейших фундаментальных исследований, так и для потенциального практического применения. В рамках фундаментальных изысканий необходимо изучить механизмы участия ПК М и ПК Сi в обеспечении и росте биологической агрессивности диффузных глиом. В клинической плоскости требуются дополнительные исследования для создания эффективных диагностических подходов, базирующихся на выявлении активности экспрессии ПК МЦ и ПК $\mathrm{Ci}$, а также лечебных препаратов, ингибирующих их активность в глиомных клетках. Дальнейшая разработка данных вопросов позволит создать принципиально новые, по-настоящему эффективные средства прецизионной диагностики и таргетной терапии глиом в рамках концепции персонализированной медицины. 01034 мк.

Исследование выполнено при финансовой поддержке РФФИ в рамках научного проекта № 18-29-

\section{Список литературы}

1. Ostrom Q.T., Gittleman H., Liao P., Vecchione-Koval T., Wolinsky Y., Kruchko C., Barnholtz-Sloan J.S. CBTRUS Statistical Report: Primary brain and other central nervous system tumors diagnosed in the United States in 2010-2014. Neuro Oncol. 2017. V. 19(suppl_5). P. v1v88. DOI: 10.1093/neuonc/nox158.

2. Hirai T., Chida K. Protein kinase Czeta (PKCzeta): activation mechanisms and cellular functions. J. Biochem. 2003. V. 133(1). P. 1-7. 
3. Zhang Y, Zong W, Zhang L, Ma Y, Wang J. Protein kinase M $\zeta$ and the maintenance of long-term memory. Neurochem Int. 2016. V. 99. P. 215 220. DOI: 10.1016/j.neuint.2016.07.007. 4. $\quad$ Wang Y.X., Zhang X.R., Zhang Z.J., Li L., Xi G.J., Wu D., Wang Y.J. Protein kinase M $\zeta$ is involved in the modulatory effect of fluoxetine on hippocampal neurogenesis in vitro. Int. J. Neuropsychopharmacol. 2014. V. 17(9). P. 1429-1441.

5. $\quad$ Ni S., Chen L., Li M., Zhao W., Shan X., Wu M., Cheng J., Liang L., Wang Y., Jiang W., Zhang J., Ni R. PKC iota promotes cellular proliferation by accelerated G1/S transition via interaction with CDK7 in esophageal squamous cell carcinoma. Tumour Biol. 2016. V. 37(10). P. 13799-13809.

6. Baldwin R.M., Barrett G.M., Parolin D.A., Gillies J.K., Paget J.A., Lavictoire S.J., Gray D.A., Lorimer I.A. Coordination of glioblastoma cell motility by PKCr. Mol Cancer. 2010. V. 9. P. 233.

7. Phillips E., Lang V., Bohlen J., Bethke F., Puccio L., Tichy D., Herold-Mende C., Hielscher T., Lichter P., Goidts V. Targeting atypical protein kinase C iota reduces viability in glioblastoma stem-like cells via a notch signaling mechanism. Int. J. Cancer. 2016. V. 139(8). P. 1776-1787.

8. McCray A.N., Desai S., Acevedo-Duncan M. The interruption of PKC-ı signaling and TRAIL combination therapy against glioblastoma cells. Neurochem Res. 2014. V. 39(9). P. 16911701.

9. Никитин П.В., Рыжова М.В., Мурадян М.А., Галстян С.А., Зубова И.В. Пилоидные астроцитомы и прот. №. 2. URL: http://science-education.ru/ru/article/view?id=28784 (дата обращения: 27.04.2020). DOI: 10.17513/spno.28784.

10. Никитин П.В., Рыжова М.В., Мурадян М.А., Дациева А.А., Галстян С.А., Зубова И.В. Протеинкиназа C iota: новый перспективный диагностический маркер у пациентов с пилоидными астроцитомами // Международный журнал прикладных и фундаментальных исследований. 2019. № 4. С. 135-139. DOI: 10.17513/mjpfi.12711. 